\title{
P02.05. Clinical practice outcomes of an individualized integrative intervention for chronic pain: results from the BraveNet PBRN
}

\author{
D Abrams* BraveNet Practice Based Research Network \\ From International Research Congress on Integrative Medicine and Health 2012 \\ Portland, Oregon, USA. 15-18 May 2012
}

\section{Purpose}

Chronic pain is one of the main conditions for which patients seek integrative medicine care. Many integrative medicine centers rank chronic pain as the complaint that they treat most effectively. We evaluated the impact of an individualized integrative intervention for chronic pain.

\section{Methods}

Patients seeking their initial treatment for chronic pain at one of the nine centers in an integrative medicine practice-based research network were eligible. Enrolled patients received a personalized integrative medicine intervention over the 24-week study period. In addition to the Brief Pain Inventory (BPI), participants also completed the SF-12, PSS-4, CES-D 20 and various numerical rating scales. Repeated measures analyses were used to assess data from baseline, week 6 , week 12 and week 24 visits.

\section{Results}

252 participants completed the 24-week study. Participants were predominantly female $(74 \%)$ with an average age of 49.8 years and 8.6 years of chronic pain. Pain was mainly in the axial skeleton, shoulders, knees and hips. The integrative intervention included combinations of acupuncture, massage, chiropractic manipulation, yoga, supplements (especially vitamin D3 and fish oil) and others. At baseline, median BPI Severity and Interference scores were both 5 ( $5=$ moderate, scored on $0-10$ scale). By 24 weeks, BPI Severity decreased $20 \%$ to $4(\mathrm{p}=0.0006)$ and Interference decreased $40 \%$ to $3(\mathrm{p}<0.0001)$. Where $52 \%$ had symptoms suggestive of depression at baseline, only $35 \%$ did at week $24(\mathrm{p}<0.0001)$. Both the mental and physical components of the SF-12 improved significantly

University of California, San Francisco, San Francisco, USA $(\mathrm{p}<0.0001)$ as did perceived stress $(\mathrm{p}<0.0001)$, sleep $(p<0.006)$, fatigue $(p<0.0001)$ and sense of control $(\mathrm{p}<0.0001)$.

\section{Conclusion}

An individualized integrative medicine intervention successfully decreased chronic pain in participants with long-standing symptoms. Consistent with the suggestion that integrative interventions frequently impact on more than one endpoint, significant and consistent improvement was also documented in symptoms of depression, stress, and fatigue with positive effects on quality of life and sense of control.

Published: 12 June 2012

\section{doi:10.1186/1472-6882-12-S1-P61}

Cite this article as: Abrams and : P02.05. Clinical practice outcomes of an individualized integrative intervention for chronic pain: results from the BraveNet PBRN. BMC Complementary and Alternative Medicine 201212 (Suppl 1):P61.

Submit your next manuscript to BioMed Central and take full advantage of:

- Convenient online submission

- Thorough peer review

- No space constraints or color figure charges

- Immediate publication on acceptance

- Inclusion in PubMed, CAS, Scopus and Google Scholar

- Research which is freely available for redistribution 